\title{
Bounded Rationality and Robust Mechanism Design: An Axiomatic Approach
}

\author{
By LUYAO ZHANG AND DAN LEVIN *
}

\section{Online Appendices}

I. Appendix A

The crucial part of the proof is that (i) implies (ii). First, since Axiom 1, 4, 5 implies von Neumann-Morgenstern's three axioms on lotteries, it follows directly from their theory (and the fact that $\digamma^{c}$ and $Z$ are isomorphic) that there exists an affine function $u: Z \rightarrow R$, such that for all $p, q \in \digamma^{c}: p \succsim q$ iff $u(p) \geq u(q)$. Moreover, $u$ is cardinally unique. By Axiom 2, $u$ is not a constant function. For any constant act $f \in \digamma^{c}, V(f)=u(f)$, satisfying (1) for any $a(f) \in[0,1]$. So $V(f)$ calibrates the preference on $\digamma^{c}$.

For any $f \in \digamma \backslash \digamma^{c}$, pick constant acts $f^{\text {best }}$, $f^{\text {worst }} \in \digamma^{c}$ that always generate the most and least preferred outcomes given $f$ is chosen. Formally, $f^{\text {best }} \in\{p \mid p \succsim q, \forall q \in$ $C(f)\}$ and $f^{\text {worst }} \in\{h \mid h \precsim q, \forall q \in C(f)\}$. For $f \in \digamma^{e} \backslash \digamma^{c}$, by the definition of $\digamma^{e}, f^{\text {best }} \sim f^{\text {worst }}$ which implies $u\left(f^{\text {best }}\right)=u\left(f^{\text {worst }}\right)$ and by Axiom $2, f \sim f^{\text {best }} \sim$ $f^{\text {worst }}$. So $V(f)=u\left(f^{\text {best }}\right)=u\left(f^{\text {worst }}\right)$ satisfying (1) for any $a(f) \in[0,1]$. Hence $V(f)$ also calibrates the preference on $F^{e}$.

Finally, for $f \in \digamma \backslash \digamma^{e}$, by the definition of $F^{e}, f^{\text {worst }} \prec f^{\text {best }}$. And by Axiom 3, $f^{\text {worst }} \precsim f \precsim f^{\text {best }}$.

LEMMA 1: for $f \in F \backslash F^{e}$, Axiom 2-5 imply there exists a unique $\beta^{*} \in[0,1]$ such that $f \sim \beta^{*} f^{\text {best }}+\left(1-\beta^{*}\right) f^{\text {worst }}$.

PROOF:

First since $u\left[\beta f^{\text {best }}+(1-\beta) f^{\text {worst }}\right]=\beta u\left(f^{\text {best }}\right)+(1-\beta) u\left(f^{\text {worst }}\right)$, so for $0 \leq$ $a<b \leq 1, b f^{\text {best }}+(1-b) f^{\text {worst }} \succ a f^{\text {best }}+(1-a) f^{\text {worst }}$. Then it ensures that if $\beta^{*}$ exists, it is unique.

If $f \sim f^{\text {best }}$, then $\beta^{*}=1$ works. The same way around, if $f \sim f^{\text {worst }}$, then $\beta^{*}=0$ works. Otherwise, $f^{\text {worst }} \prec f \prec f^{\text {best }}$. Define

$$
\beta^{*}=\sup \left\{\beta \in[0,1]: f \succeq \beta f^{\text {best }}+(1-\beta) f^{\text {worst }}\right\} .
$$

\footnotetext{
* Zhang: Ohio State University, 410 Arps Hall, 1945 N. High St, Columbus, OH 43220 (email: sunshineluyao@gmail.com); Levin: Ohio State University, 433B Arps Hall, 1945 N. High St, Columbus, OH 43210 (email: Levin.36@osu.edu). The authors thank Ariel Rubinstein, Yaron Azrieli, Paul Healy and Ian Krajbich for useful discussions on the content of this paper and much more.
} 
Since $\beta=0$ is in the set, we aren't taking a sup over an empty set. By the definition of $\beta^{*}$ if $1 \geq \beta>\beta^{*}$, then $f \prec \beta f^{\text {best }}+(1-\beta) f^{\text {worst }}$. Moreover, by the same argument to prove uniqueness above, if $0 \leq \beta<\beta^{*}$, then $f \succ \beta f^{\text {best }}+(1-\beta) f^{\text {worst }}$. To see this, note that if $0 \leq \beta<\beta^{*}$, then there exists $\beta^{\prime}$ such that $0 \leq \beta<\beta^{\prime} \leq \beta^{*}$ and $f \succsim \beta^{\prime} f^{\text {best }}+\left(1-\beta^{\prime}\right) f^{\text {worst }}$ by the definition of $\beta^{*}$. And $\beta<\beta^{\prime}$ implies that $f \succsim \beta^{\prime} f^{\text {best }}+\left(1-\beta^{\prime}\right) f^{\text {worst }} \succ \beta f^{\text {best }}+(1-\beta) f^{\text {worst }}$.

There are three possibilities to consider.

(1). Suppose $\beta^{*} f^{\text {best }}+\left(1-\beta^{*}\right) f^{\text {worst }} \succ f \succ f^{\text {worst }}$, then by Axiom 5 there exists $b \in(0,1)$ such that $b\left[\beta^{*} f^{\text {best }}+\left(1-\beta^{*}\right) f^{\text {worst }}\right]+(1-b) f^{\text {worst }}=b \beta^{*} f^{\text {best }}+(1-$ $\left.b \beta^{*}\right) f^{\text {worst }} \succ f$. But $b \beta^{*}<\beta^{*}$, so by the previous argument $f \succ b \beta^{*} f^{\text {best }}+(1-$ $\left.b \beta^{*}\right) f^{\text {worst }}$. Contradiction.

(2). Suppose instead that $f^{\text {best }} \succ f \succ \beta^{*} f^{\text {best }}+\left(1-\beta^{*}\right) f^{\text {worst }}$. Then by Axiom 5, there exists $a \in(0,1)$ such that $f \succ a\left[\beta^{*} f^{\text {best }}+\left(1-\beta^{*}\right) f^{\text {worst }}\right]+(1-a) f^{\text {best }}=$ $\left(1-a\left(1-\beta^{*}\right)\right) f^{\text {best }}+a\left(1-\beta^{*}\right) f^{\text {worst }}$. Since $\left(1-a\left(1-\beta^{*}\right)\right)>\beta^{*}$, we have from above that $\left(1-a\left(1-\beta^{*}\right)\right) f^{\text {best }}+a\left(1-\beta^{*}\right) f^{\text {worst }} \succ f$. Contradiction.

(3). This leaves us with the third possibility (which is what we want) namely that $f \sim \beta^{*} f^{\text {best }}+\left(1-\beta^{*}\right) f^{\text {worst }}$.

Proof of lemma 1 ends.

Follows the argument of lemma 1 , then $V(f)=V\left[\beta^{*} f^{\text {best }}+\left(1-\beta^{*}\right) f^{\text {worst }}\right]$. Since $\left[\beta^{*} f^{\text {best }}+\left(1-\beta^{*}\right) f^{\text {worst }}\right] \in \digamma^{c}$,

$$
V\left[\beta^{*} f^{\text {best }}+\left(1-\beta^{*}\right) f^{\text {worst }}\right]=u\left[\beta^{*} f^{\text {best }}+\left(1-\beta^{*}\right) f^{\text {worst }}\right]
$$

Moreover, since $u$ is affine,

$$
u\left[\beta^{*} f^{\text {best }}+\left(1-\beta^{*}\right) f^{\text {worst }}\right]=\beta^{*} u\left(f^{\text {best }}\right)+\left(1-\beta^{*}\right) u\left(f^{\text {worst }}\right) .
$$

Then, by the definition of $f^{\text {best }}$ and $f^{\text {worst }}$,

$$
\min _{p \in C(f)} u(p)=u\left(f^{\text {worst }}\right)<u\left(f^{\text {best }}\right)=\max _{p \in C(f)} u(p) .
$$

So

$$
u\left[\beta^{*} f^{\text {best }}+\left(1-\beta^{*}\right) f^{\text {worst }}\right]=\beta^{*} \max _{p \in C(f)} u(p)+\left(1-\beta^{*}\right) \min _{p \in C(f)} u(p) .
$$

Then

$$
V(f)=\beta^{*} \max _{p \in C(f)} u(p)+\left(1-\beta^{*}\right) \min _{p \in C(f)} u(p) .
$$

So $\alpha(f)=\beta^{*}$ works and is uniquely determined.

\section{Appendix B}

$(\Longrightarrow)$ If $s_{i}^{*}$ is an obviously dominant strategy, then by (2) and the obvious monotonicity axiom, (3) is satisfied. 
( $\Longleftarrow$ ) If (3) holds, assume by contradiction that $s_{i}^{*}$ is not an obviously dominant strategy. Then there exists an information set $I \in \vartheta_{i}\left(s_{i}^{*}\right)$, a deviating strategy $s_{i}^{\prime} \in$ $S_{i}(I)\left[s_{i}^{*}(I)\right]^{c}$ such that $\inf _{\left(s_{-i}, r_{n}\right) \in[I]} u_{i}\left(s_{i}^{*}, s_{-i}, \omega_{n}\right)<\sup _{\left(s_{-i}, r_{n}\right) \in[I]} u_{i}\left(s_{i}^{\prime}, s_{-i}, \omega_{n}\right)$.

Then we can find an obvious preference represented by (1) with $\alpha\left(s_{i}^{*}\right)=0$ and $\alpha\left(s_{i}^{\prime}\right)=$ 1 such that $V\left(s_{i}^{*}\right)<V\left(s_{i}^{\prime}\right)$. So $s_{i}^{*} \prec_{[I]} s_{i}^{\prime}$. Contradiction.

\section{Appendix C}

Since $u_{i}\left(s_{i}^{*}, s_{-i}^{*}, \omega_{n}\right) \geq \inf _{\omega_{n}^{\prime} \in \Omega_{N}} u_{i}\left(s_{i}^{*}, s_{-i}^{*}, \omega_{n}^{\prime}\right)$ and $u_{i}\left(s_{i}^{\prime}, s_{-i}^{*}, \omega_{n}\right) \leq \sup _{\left(s_{-i}, \omega_{n}^{\prime}\right) \in[I]} u_{i}\left(s_{i}^{\prime}, s_{-i}, \omega_{n}^{\prime}\right)$ for any $s_{i}^{\prime} \in S_{i}(I)\left[s_{i}^{*}(I)\right]^{c}$ and $\omega_{n} \in \Omega_{N}$, (4) implies (5). 